\title{
Comparative genomics profiling of clinical isolates of Aeromonas salmonicida using DNA microarrays
} John HE Nash*1, Wendy A Findlay ${ }^{1}$, Christian C Luebbert ${ }^{1}$, Oksana L Mykytczuk ${ }^{1}$, Simon J Foote ${ }^{1}$, Eduardo N Taboada ${ }^{1}$, Catherine D Carrillo' ${ }^{1}$, Jessica M Boyd ${ }^{2}$, Duncan J Colquhoun ${ }^{3}$, Michael E Reith ${ }^{2}$ and Laura L Brown ${ }^{2}$

\author{
Address: ${ }^{1}$ Institute for Biological Sciences, National Research Council of Canada, 100 Sussex Drive, Ottawa, Ontario, K1A 0R6, Canada, ${ }^{2}$ Institute \\ for Marine Biosciences, National Research Council of Canada, 1411 Oxford Street, Halifax, Nova Scotia, B3H 3Z1, Canada and ${ }^{3}$ National \\ Veterinary Institute, Department for Fish Health, Post Box 8156 Dep., 0033 Oslo, Norway \\ Email: John HE Nash* - john.nash@nrc-cnrc.gc.ca; Wendy A Findlay - wendy.findlay@nrc-cnrc.gc.ca; \\ Christian C Luebbert - christian.luebbert@nrc-cnrc.gc.ca; Oksana L Mykytczuk - oksana.mykytczuk@nrc-cnrc.gc.ca; \\ Simon J Foote - simon.foote@nrc-cnrc.gc.ca; Eduardo N Taboada - ed.taboada@nrc-cnrc.gc.ca; Catherine D Carrillo - cathy.carrillo@gmail.com; \\ Jessica M Boyd - jessica.boyd@nrc-cnrc.gc.ca; Duncan J Colquhoun - duncan.colquhoun@vetinst.no; Michael E Reith - michael.reith@nrc- \\ cnrc.gc.ca; Laura L Brown - laura.brown@nrc-cnrc.gc.ca \\ * Corresponding author
}

Published: 07 March 2006

BMC Genomics2006, 7:43 doi:10.1186/147/-2164-7-43

This article is available from: http://www.biomedcentral.com/I47I-2164/7/43

(c) 2006Nash et al; licensee BioMed Central Ltd.

This is an Open Access article distributed under the terms of the Creative Commons Attribution License (http://creativecommons.org/licenses/by/2.0), which permits unrestricted use, distribution, and reproduction in any medium, provided the original work is properly cited.

\begin{abstract}
Background: Aeromonas salmonicida has been isolated from numerous fish species and shows wide variation in virulence and pathogenicity. As part of a larger research program to identify virulence genes and candidates for vaccine development, a DNA microarray was constructed using a subset of 2024 genes from the draft genome sequence of $A$. salmonicida subsp. salmonicida strain $A 449$. The microarray included genes encoding known virulence-associated factors in $A$. salmonicida and homologs of virulence genes of other pathogens. We used microarray-based comparative genomic hybridizations (M-CGH) to compare selected A. salmonicida sub-species and other Aeromonas species from different hosts and geographic locations.
\end{abstract}

Results: Results showed variable carriage of virulence-associated genes and generally increased variation in gene content across sub-species and species boundaries. The greatest variation was observed among genes associated with plasmids and transposons. There was little correlation between geographic region and degree of variation for all isolates tested.

Conclusion: We have used the M-CGH technique to identify subsets of conserved genes from amongst this set of $A$. salmonicida virulence genes for further investigation as potential vaccine candidates. Unlike other bacterial characterization methods that use a small number of gene or DNA-based functions, M-CGH examines thousands of genes and/or whole genomes and thus is a more comprehensive analytical tool for veterinary or even human health research. 


\section{Background}

Aeromonas salmonicida, the causative agent of furunculosis in salmonid fish, is a non-motile, Gram-negative bacterium, and one of the most studied bacterial pathogens of fish. Furunculosis is an important disease in wild and cultured stocks of fish with the potential for severe negative economic impact. The Canadian Aquaculture Industry Alliance estimated the total direct and indirect costs of infectious diseases within the Canadian aquaculture industry at over $\$ 400 \mathrm{M}$ annually, with furunculosis contributing approximately $\$ 4 \mathrm{M}$ annually to these losses [1]. A. salmonicida is not limited to salmonids and many species of fish are affected. Several excellent reviews of $A$. salmonicida and furunculosis are available [2-4].

Although Bergey's Manual of Systematic Bacteriology [5] recognizes five subspecies of $A$. salmonicida: salmonicida, achromogenes, masoucida, smithia, and pectinolytica, many laboratories currently classify A. salmonicida subsp. salmonicida as "typical" and any isolate deviating phenotypically as "atypical". Morphological and biochemical differences are used to distinguish typical and atypical isolates. These are pigment production, colony size and growth rate, haemolysis, and sucrose fermentation $[4,6,7]$. A. salmonicida subsp. salmonicida (i.e. typical) isolates grow well on blood agar with large colonies, produce brown, diffusible pigment, are haemolytic and do not ferment sucrose. Historically, typical strains are thought to be extremely homogenous $[8,9]$, and therefore any deviation in any of these characteristics has been considered enough evidence to classify a strain as "atypical" $[8,10]$. However, some of these parameters are subjective, and are largely based on the experience of the operator/microbiologist, possibly leading to misclassification. Molecular techniques are not yet used on a regular basis in many laboratories that type A. salmonicida. Although typical isolates are generally phenotypically homogenous some variation does exist [10], particularly with regard to the production of hemolysin and degradation of casein. Antibiotic resistance patterns have shown potential as epizootiological markers in specific geographical origins. Typing schemes based on biochemical and other phenotypic methods are dependent on many factors, including plastic bacterial phenotypes and the often low consistency of inter-laboratory testing [11].

Genetic analysis provides a more stable basis for microbiological investigation than phenotypic methods. Several molecular techniques, including finger-printing by Randomly Amplified DNA Polymorphism (RAPD-PCR) [12,13], Amplified Fragment Length Polymorphism (AFLP) [14], Pulsed-Field Gel Electrophoresis (PFGE) $[9,15]$, Restriction Enzyme Fragmentation Patterns (REFP) [16], plasmid profiling [17,18], and ribotyping $[19,20]$, have been used to study different strains of A. sal- monicida. While the results generally support the phenotypical evidence that typical strains are genetically homogenous and may well be clonal, and that atypical isolates are heterogeneous, there is little congruence between the techniques in establishing relationships between subspecies, strains and isolates. Austin et al. [1998] showed that among 52 isolates of atypical A. salmonicida taken from a wide host and geographical range, there was no agreement between PCR, RAPD, ribotyping, or phenotypic typing methods [8].

The use of genome arrays containing whole genomes or large sets of genes, either as a result of high-coverage genome sequencing or selected after suppressive subtractive hybridization have been used to study genome variability among strains of bacterial pathogens, including Campylobacter jejuni [21], Flavobacterium psychrophilum [22], Listeria monocytogenes [23], and Burkholderia species [24]. To examine the genomic diversity of virulence factors among clinical isolates of $A$. salmonicida and other aeromonads, we constructed a DNA microarray of 2024 selected virulence-related genes from $A$. salmonicida subsp. salmonicida strain A449. A449 is a wild-type typical virulent clinical isolate which has been sequenced and it is currently undergoing annotation.

We are undertaking a research program to examine the molecular mechanisms of interaction between A. salmonicida and Atlantic salmon (Salmo salar L.). The applied goal of this program is to develop vaccines, vaccine delivery systems and other health management tools. In order to develop vaccines we must first identify virulence-associated genes as potential vaccine candidates, the process known as "reverse vaccinology" [25]. Accurate typing is important in searching for vaccine candidates if there are known differences in pathogenicity of the sub-species, or if there is variation between the degree of conservation of virulence genes within each subspecies. Although all subspecies of $A$. salmonicida have been implicated in clinical cases in fishes, Aeromonas salmonicida subsp. salmonicida is more prevalent within salmonids and "typical" isolates are more often associated with disease outbreaks in salmon [3]. Moreover, there are indications that there are differences in the susceptibility and immune response of salmonids and other fishes to "atypical" isolates $[14,26]$. Therefore it is essential that any characterization or typing schemes be accurate, if health management strategies are to be based, even partly, on those schemes.

We used M-CGH to study the genetic relationships between Aeromonas species, subspecies and strains based on gene conservation profiles and to examine genomic diversity. We compared strains and isolates from selected geographic areas and host species to explore correlations between geographic or host origin and conservation or 
Table I: Aeromonas strains analyzed by M-CGH in this study

\begin{tabular}{|c|c|c|c|c|}
\hline Strain & Species & Host species & Origin & Source' \\
\hline A449 & A. salmonicida salmonicida & Salmo trutta (brown trout) & France & $\mathrm{CC}^{4}$ \\
\hline ATCC 51108 & A. bestiarum & diseased fish & Scotland & $\mathrm{CC}^{5}$ \\
\hline ATCC 15468 & A. caviae & guinea pig & France & $\mathrm{CC}^{5}$ \\
\hline ATCC 33659 & A. salmonicida achromogenes & S. trutta & USA & $\mathrm{CC}^{5}$ \\
\hline N25 17 & A. salmonicida atypical & Hippoglossus hippoglossus (Atlantic halibut) & Norway & $\mathrm{CC}^{6}$ \\
\hline N4705 & A. salmonicida atypical & Scophthalmus maximus (Turbot) & Norway & $\mathrm{CC}^{6}$ \\
\hline ATCC 27013 & A. salmonicida masoucida & Oncorhynchus masoucida (Masou salmon) & Japan & $\mathrm{CC}^{7}$ \\
\hline ATCC 33658 & A. salmonicida salmonicida & Salmo salar (Atlantic salmon) & France & $\mathrm{CC}^{7}$ \\
\hline ATCC 5I4I3 & A. salmonicida salmonicida & S. trutta & Finland & $\mathrm{CC}^{7}$ \\
\hline 80204-I & A. salmonicida salmonicida & S. salar & $\mathrm{NB}^{2}$ & $\mathrm{LD}^{7}$ \\
\hline BC6I 29 & A. salmonicida salmonicida & S. salar & $\mathrm{BC}^{3}$ & $\mathrm{CC}^{8}$ \\
\hline NI7/8 & A. salmonicida salmonicida & S. salar & Norway & $\mathrm{CC}^{6}$ \\
\hline N246I & A. salmonicida salmonicida & S. maximus & Norway & $\mathrm{CC}^{6}$ \\
\hline N2660 & A. salmonicida salmonicida & S. salar & Norway & $\mathrm{CC}^{6}$ \\
\hline N3395 & A. salmonicida salmonicida & S. salar & Norway & $\mathrm{CC}^{4}$ \\
\hline N4399 & A. salmonicida salmonicida & S. salar & Norway & $\mathrm{CC}^{6}$ \\
\hline SS70.I & A. salmonicida salmonicida & Oncorhynchus kisutch (Coho salmon) & $\mathrm{NB}^{2}$ & $\mathrm{LD}^{7}[30]$ \\
\hline
\end{tabular}

I Clinical Case (CC) or Lab-Derived (LD)

2 New Brunswick, Canada (NB)

3 British Columbia, Canada (BC)

${ }^{4}$ Dr. William Kay, University of Victoria, BC;

${ }^{5}$ American Type Culture Collection (ATCC)

${ }^{6}$ Norwegian Veterinary Institute, Oslo, Norway

7 Dr. Gilles Olivier, Department of Fisheries and Oceans, Moncton, New Brunswick

8 Dr. Joanne Constantine, BC Ministry of Agriculture, Food and Fisheries, Victoria, British Columbia

diversity of genes. These strains were selected to provide a diverse sample of clinical and laboratory isolates from the differing geographic regions and host species infected. Our goal was to identify a set of virulence-associated genes conserved across these strains to consider for future consideration as vaccine candidates. We hypothesized greater variability of these virulence genes between subspecies and no correlation between the "typical" and "atypical" classifications and gene variability. We also hypothesized positive correlation between the degree of variability and the functional category of the variable genes involved.

\section{Results}

Comparative genomic hybridization (M-CGH) profiles for each of the Aeromonas isolates listed in Table 1 were obtained by competitively hybridizing labeled genomic DNA (gDNA) from the relevant isolate and from the A449 control strain to an A. salmonicida microarray comprising 2024 putative virulence genes, selected from a draft genome sequence of the wild type strain A. salmonicida subsp. salmonicida A449.

Hierarchical clustering of the seventeen Aeromonas isolates based on the overall variability in the M-CGH data is represented by the dendrogram in Figure 1A. As expected, the ten A. salmonicida subsp. salmonicida strains and the control strain A449 clustered together. One atypical strain (N4705) also clustered in this group. There is very strong support $(99 \%)$ for the clustering of the eleven A. salmoni- cida subsp. salmonicida strains with the atypical strain N4705, but much lower bootstrap values for most branches within this main cluster. Figure $1 \mathrm{~B}$ shows hierarchical clustering of the seventeen Aeromonas samples based only on "chromosomal" genes, after genes assigned to the plasmid and transposon functional categories were removed. The ten A. salmonicida subsp. salmonicida strains cluster with A449 and the atypical strain N4705. In each dendrogram, as expected, A. bestiarum and A. caviae showed the most divergence from the main cluster, followed by A. salmonicida subsp. masoucida and A. salmonicida subsp. achromogenes, consistent with the species/ subspecies boundaries. It is interesting to note that one of the A. salmonicida atypical samples (N2517) clustered with A. salmonicida subsp. achromogenes, whereas the second atypical strain (N4705) clustered with the A. salmonicida subsp. salmonicida A449 control strain. These results suggest that neither of these should be considered A. salmonicida atypical strains.

The M-CGH data for the sixteen Aeromonas samples ordered with hierarchical clustering of the genes is shown in Figure 2. Genes were considered to be conserved if the signal differed by less than a factor of two between the tester and the control (Log Ratios of between -1.0 and +1.0), as described by Taboada et al., 2004 [21]. The lower cutoff of -1.0 is fairly conservative as we have shown previously that it encompasses over $99.5 \%$ of highly conserved genes but less than $1 \%$ of missing genes [27]. To 
A

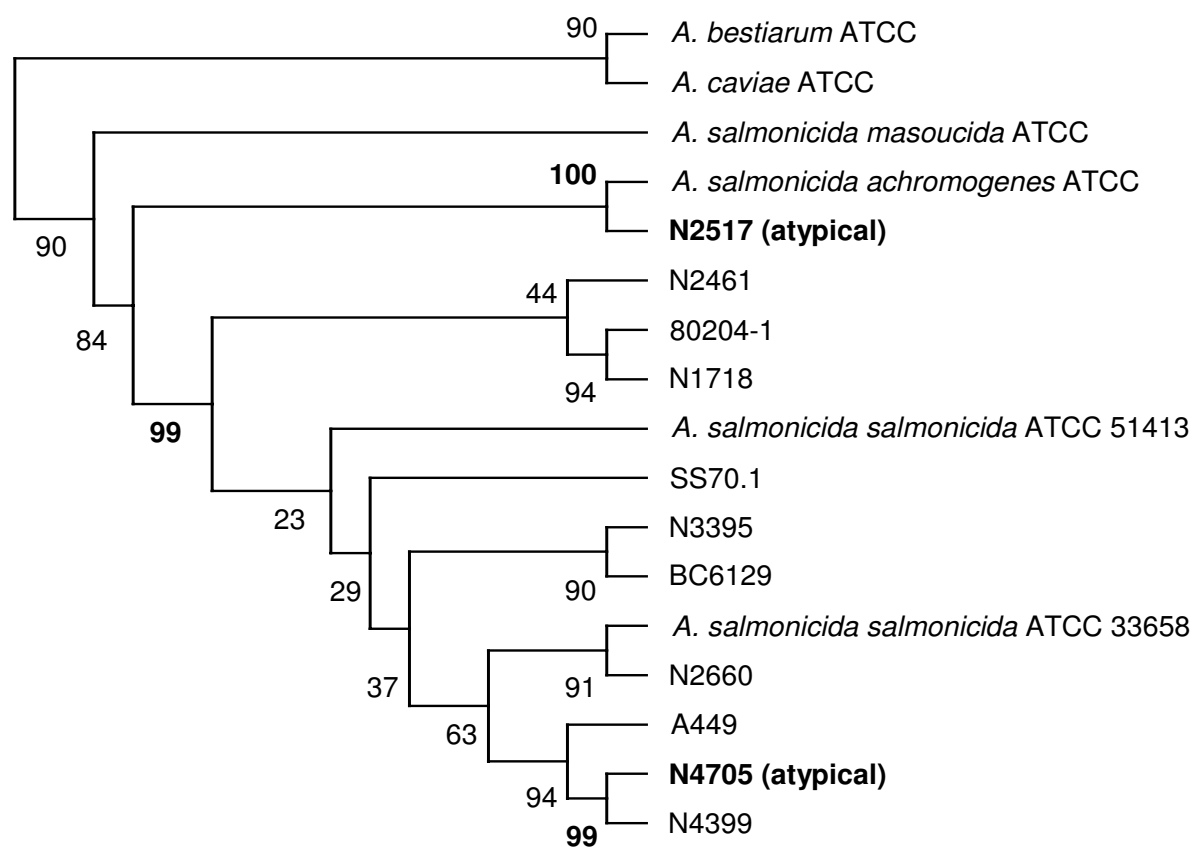

B

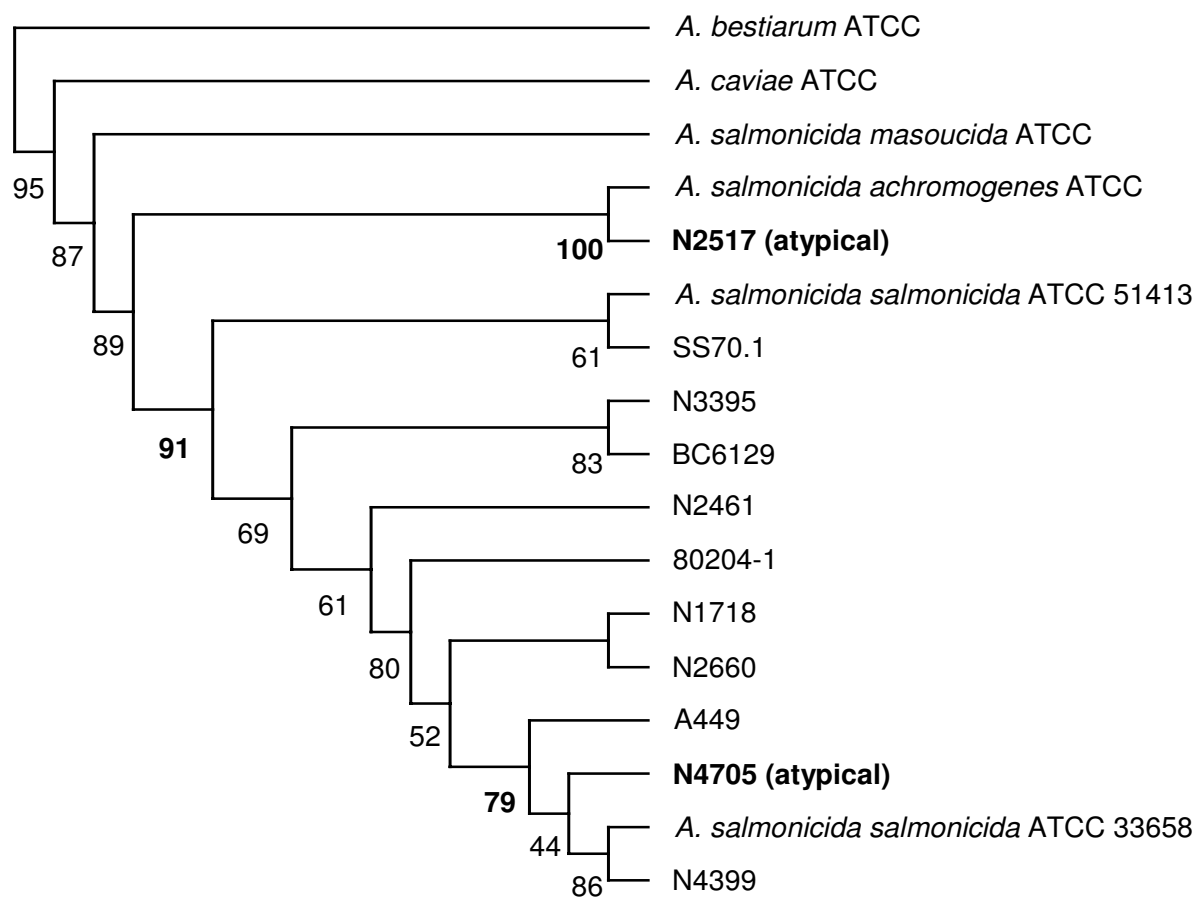

Figure I

Hierarchical clustering of Aeromonas strains based on M-CGH data for all genes on the microarray. The dendrogram was produced using the MEV software from TIGR with Euclidean distance and average linkage clustering ( $\mathrm{n}=1,000$ bootstrap iterations). Isolates in bold are atypical isolates that cluster with other known subspecies. The bootstrap values which lead to their cluster assignment are also in bold. All ATCC type strains are denoted "ATCC", and unless otherwise noted, all other isolates are A. salmonicida subsp. salmonicida. (A) Sample clustering based on all genes on the AsalChipl microarray. (B) Sample clustering based on genes not assigned to the plasmid or transposon functional categories (i.e. "chromosomal" genes). 


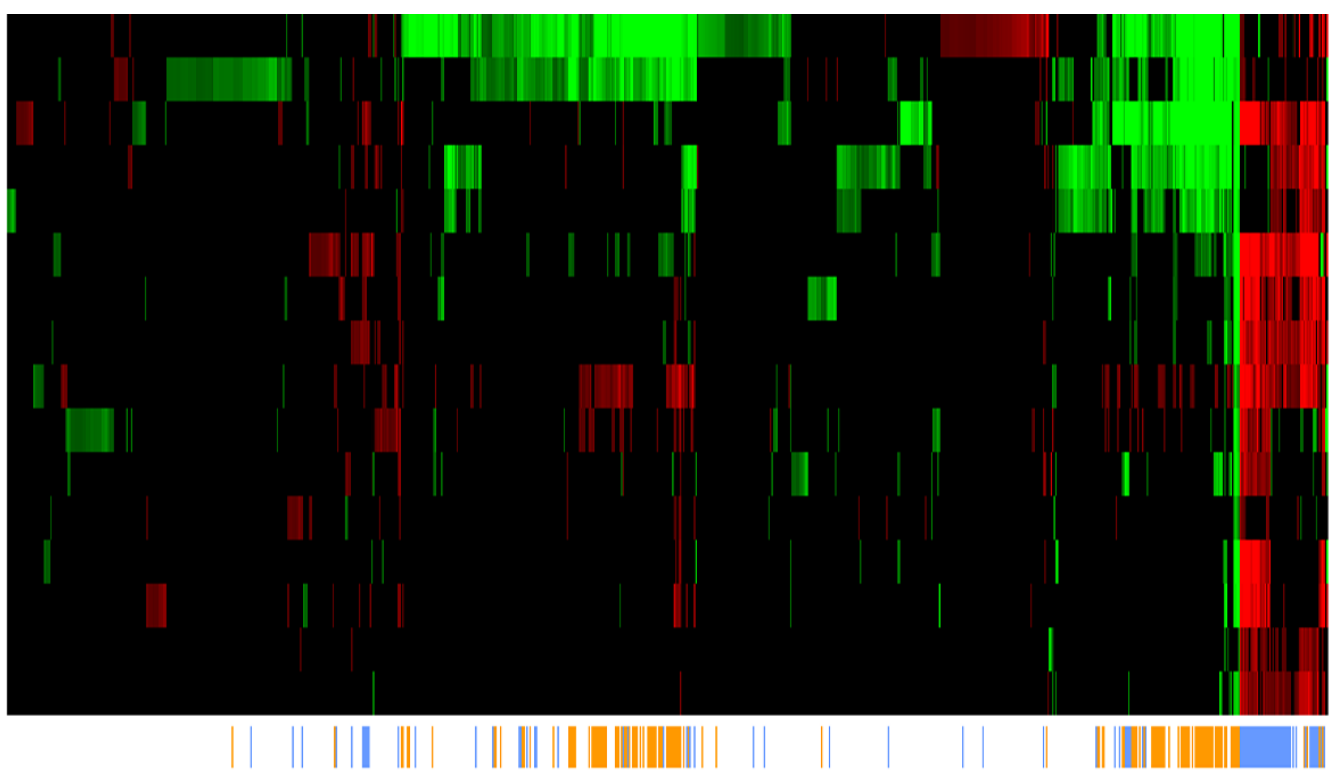

A. bestiarum

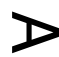

A. caviae

Asm $^{\mathrm{a}}$

Asa $^{b}$

N2517 (atypical)

N2461

80204-1

N1718

Ass $^{\complement}$ ATCC 51413

SS70.1

N3395

BC6129

Ass $^{c}$ ATCC 33658

N2660

N4705 (atypical)

N4399

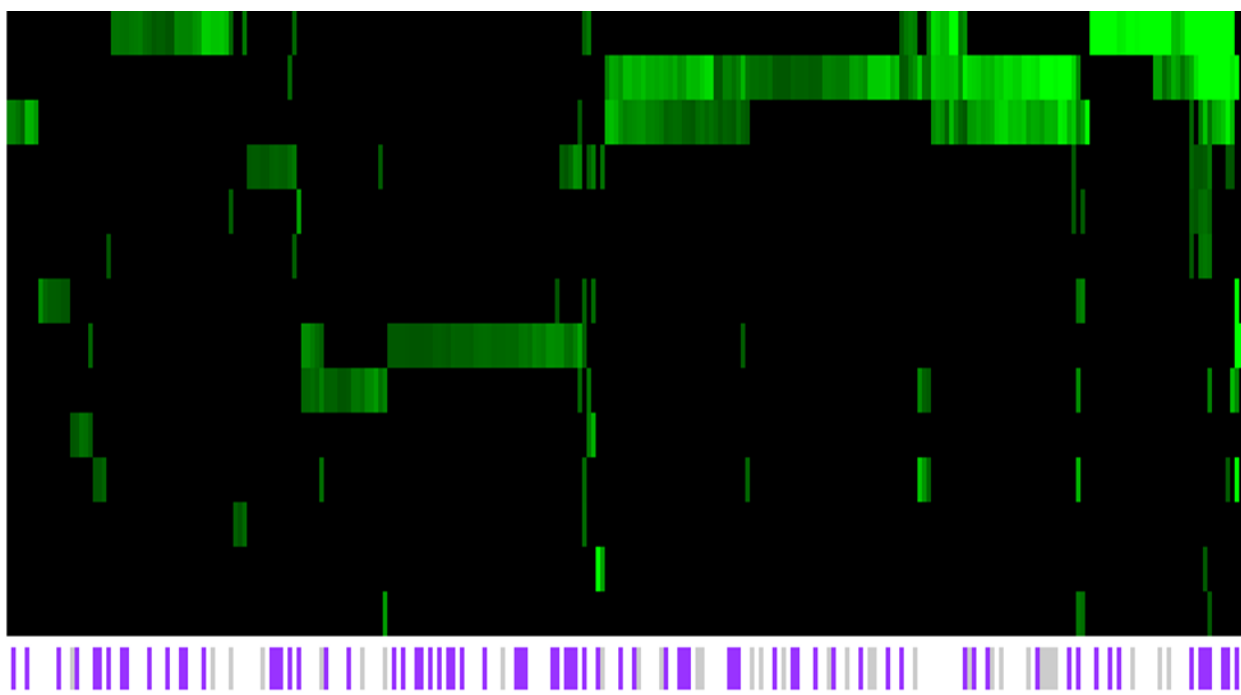

Asm $^{\mathrm{a}}$

Asa $^{\mathrm{b}}$

N2517 (atypical)

N2461

80204-1

$\mathrm{N} 1718$

Ass $^{\mathrm{C}}$ ATCC 51413

SS70.1

N3395

BC6129

Ass $^{c}$ ATCC 33658

N2660

N4705 (atypical)

N4399

\section{Figure 2}

Variable genes in Aeromonas samples. Genes which were conserved $(-\mid<$ Log Ratio $<1)$ in all samples are removed. Red indicates genes with higher signal intensity for the tester than the control strain (higher copy number than strain A449). Green indicates genes with lower signal intensity for the tester than the control (divergent in sequence or missing or lower copy number). Gene order reflects results of hierarchical clustering of genes performed as described in Materials and Methods. The strains are ordered as in Figure I, and unless otherwise noted, all other isolates are $A$. salmonicida subsp. salmonicida. ${ }^{a} A$ sm $-A$. salmonicida subsp. masoucida, ${ }^{b}$ Asa $-A$. salmonicida subsp. achromogenes, ${ }^{c}$ Ass $-A$. salmonicida subsp. salmonicida. (A) All genes which are divergent in at least one of the sixteen Aeromonas isolates. Blue bars indicate genes associated with the plasmid category and orange bars indicate genes associated with the transposon category as described in Material and Methods. (B) Subset of genes which are divergent (Log Ratio< $-I$ ) in the fourteen A. salmonicida strains and were not assigned to the plasmid or transposon functional categories. Genes predicted to code for OMPs (purple) and for flagella/pili proteins (grey) are indicated. 
Table 2: Keywords from gene annotations used to identify virulence and virulence-associated genes, and assign functional categories

\begin{tabular}{|c|c|c|}
\hline Keyword ${ }^{a}$ & Functional category & Relevance \\
\hline Aerolysin & Toxin & known virulence protein \\
\hline antibiotic & Antibiotic resistance & antibiotic resistance/susceptibility \\
\hline capsule & $\mathrm{CHO} /$ Surface factors & capsule biosynthesis/transport \\
\hline catalase & Flagella/pilin; OMP & catalase/peroxidases \\
\hline chemotax & IC protect; Toxin & chemotaxis proteins \\
\hline chitin & Other; Toxin & chitinase \\
\hline cpa & Flagella/pilin & pilus assembly complex \\
\hline dismutase & IC protect & superoxide dismutase \\
\hline extracel & Other & extracellular proteins \\
\hline ferr & Iron systems; Transport; & ferredoxins, ferric transport \\
\hline fimb & Flagella/pilin & fimbrial proteins \\
\hline flag & Flagella/pilin & flagellar proteins \\
\hline glycosyl & $\mathrm{CHO} /$ Surface factors & glycosyl transferases \\
\hline hemolysin & Toxin & hemolysin/aerolysin \\
\hline invas & OMP & invasions or invasion/adhesion \\
\hline iron & Iron systems; Transport & iron transport/binding \\
\hline Laf & Flagella/pilin & Vibrio parahaemolyticus chemotaxis protein \\
\hline Lfg & Flagella/pilin & V. parahaemolyticus flagellar hook protein \\
\hline lip & $\mathrm{CHO} /$ Surface factors & lipid/lipoprotein \\
\hline macrophage & IC protect & macrophage toxins \\
\hline membrane & OMP & outer/inner membrane proteins \\
\hline OMP & OMP & outer membrane proteins \\
\hline penicillin & Antibiotic resistance & penicillin resistance \\
\hline peroxid & IC protect ; Toxin & peroxidase \\
\hline pil & Flagella/pilin & pilin/pilus assembly protein \\
\hline plasmid & Plasmid & plasmid-encoded \\
\hline polymer & Sigma & DNA polymerase/Sigma factor \\
\hline porin & OMP & outer membrane porin protein \\
\hline protease & Other; Toxin & proteases \\
\hline pseudopilin & Secretion & part of Type II secretion system \\
\hline pul & Flagella/pilin & part of Type II secretion system \\
\hline quorum & Other & quorum sensing proteins \\
\hline receptor & OMP & membrane receptor proteins \\
\hline resistance & Antibiotic resistance & antibiotic resistance \\
\hline RTX & Toxin & RTX toxin (hemolysin) \\
\hline secret & Secretion & secretion systems/secretory proteins \\
\hline sial & $\mathrm{CHO} /$ Surface factors; Other; & sialic acid transport/synthetase \\
\hline siderophore & OMP & siderophore receptor \\
\hline sigma & Sigma & sigma factor \\
\hline SOD & IC protect & superoxide dismutase \\
\hline superoxide & IC protect & superoxide dismutase \\
\hline Tad & Flagella/pilin & Vibrio spp. pilus assembly protein \\
\hline tap & Other; Transport & $A B C$ transporter/ATP-binding protein \\
\hline toxin & Toxin & toxin genes \\
\hline transferase & $\mathrm{CHO} /$ Surface factors; Other & glycosyl and other transferases \\
\hline transport & Transport & transport proteins \\
\hline transpos & Transposon & transposases \\
\hline usher & Flagella/pilin & chaperone/usher type fimbriae \\
\hline Yop & Secretion & Type III Secretion system gene in Yersinia spp. \\
\hline
\end{tabular}

aor portions of keywords selected to include grammatical variants, e.g. invas would select invasion or invasins, etc.

highlight the variable genes, the Log Ratio value was set to 0 (black) for conserved genes, and genes which were conserved in all of the samples have been removed. Genes with Log Ratio values less than -1.0 (green) were considered to be divergent in sequence or absent from the tester strain, while those with Log Ratios values greater than
+1.0 (red) were expected to be present in higher copy number in the tester than in the control strain. As shown in Figure 2A, clusters with the highest variability across the samples correspond to plasmid- and transposon-associated genes. As expected, A. bestiarum and A. caviae have higher numbers of variable genes than the A. salmonicida 
Table 3: Number of divergent genes (Log Ratio <-I) in each strain for each functional category

A. salmonicida subsp. salmonicida

A. salmonicida atypical

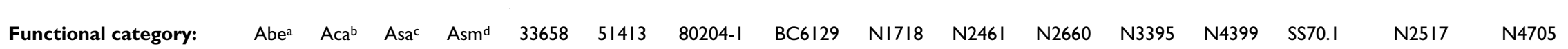

\begin{tabular}{lllllllllllllllllll}
\hline Antibiotic resist & 11 & 14 & 7 & 5 & 0 & 0 & 0 & 0 & 0 & 0 & 0 & 4 & 0 & 6
\end{tabular}

$\mathrm{CHO} /$ surface

Flagella/pilin

$50 \quad 30 \quad 29$

IC protect

Iron systems

OMP

Other

Plasmid

Secretion

Sigma

Toxin

Transport

Transposon

3

$29 \quad 1$

16

31

Total

$53 \quad 56 \quad 3$

6

4

${ }^{a}$ Abe $-A$. bestiarum

${ }^{\mathrm{b} A c a}-A$. caviae

'Asa - A. salmonicida subsp. achromogenes

dAsm - A. salmonicida subsp. masoucida 
A
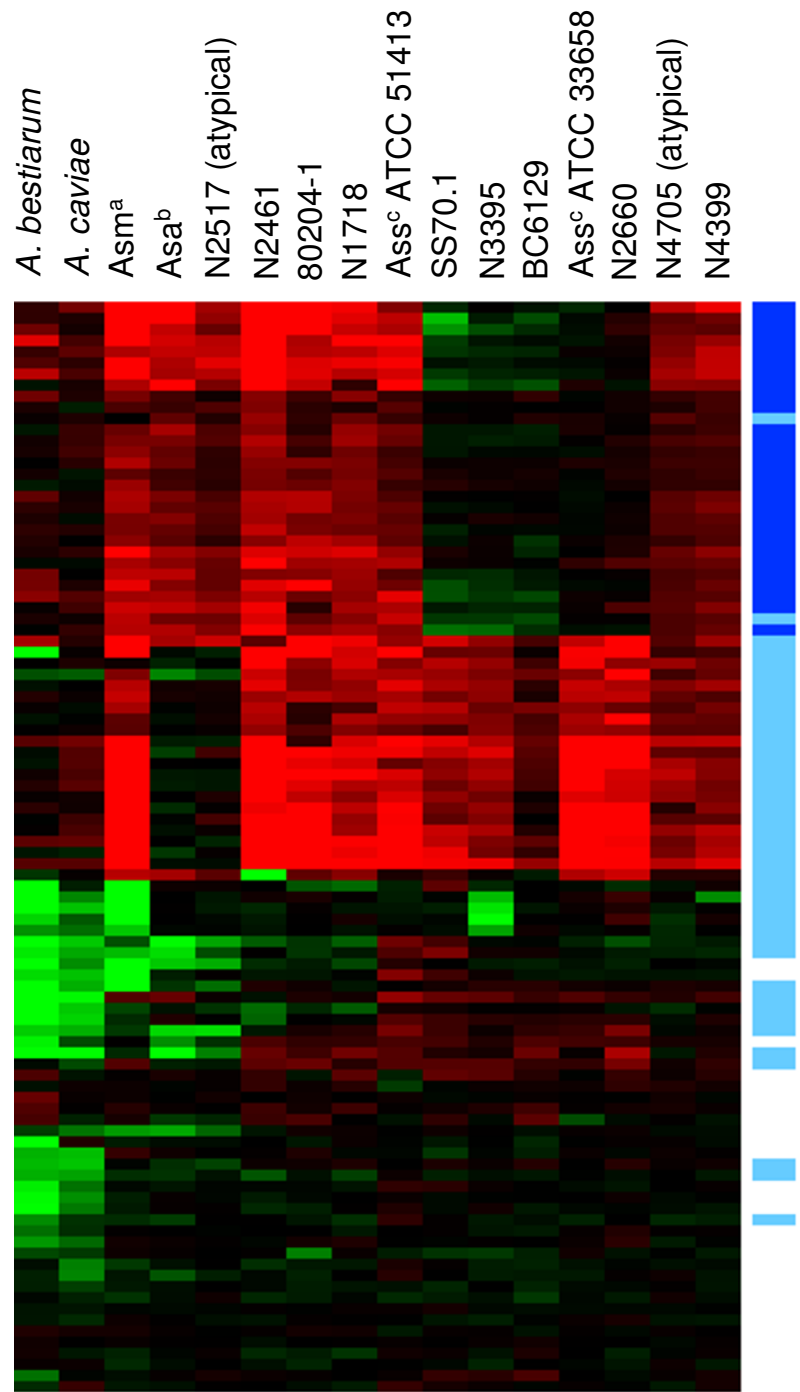
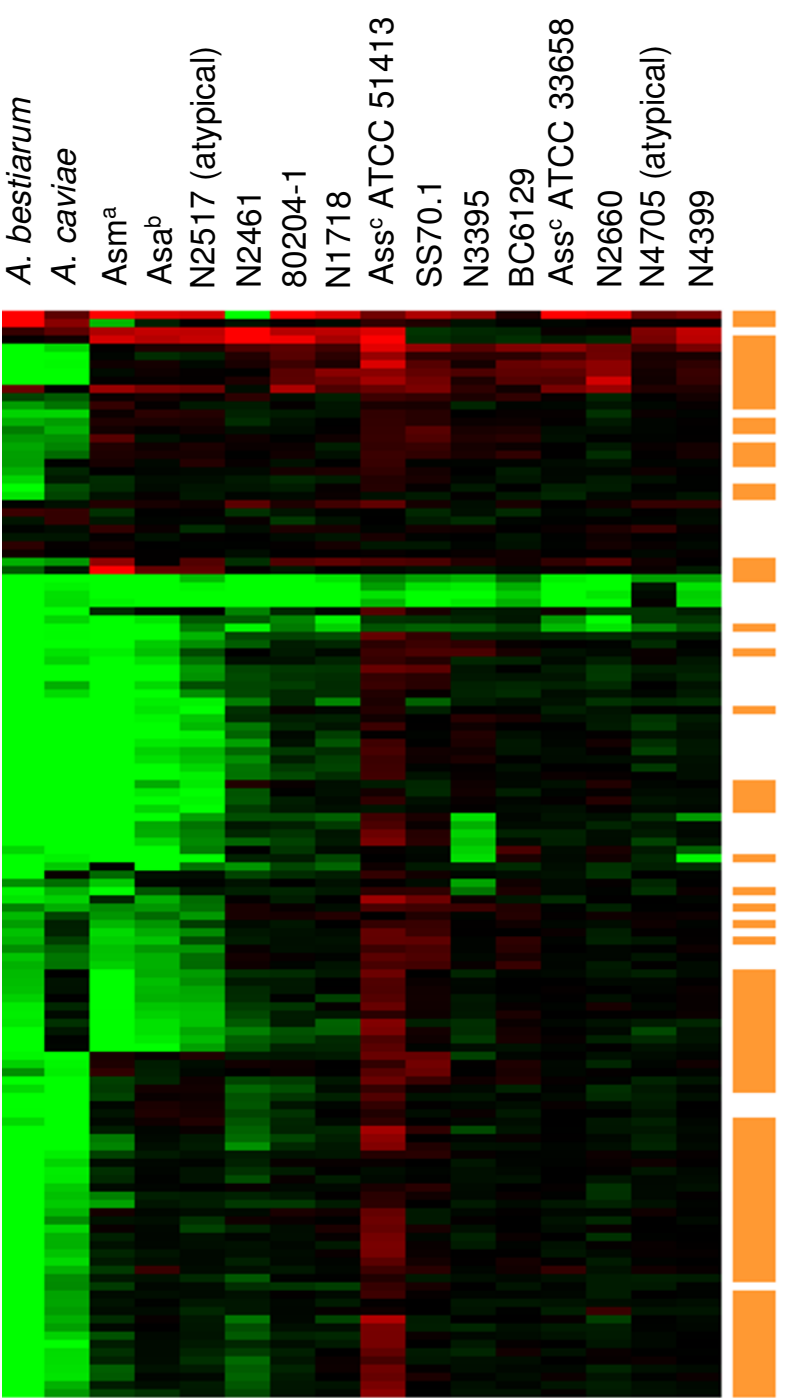

\section{Figure 3}

Variability of genes associated with plasmids and transposons in 16 Aeromonas strains and species. Red indicates genes with higher signal intensity for the tester than the control strain (higher copy number than in strain A449). Green indicates genes with lower signal intensity for the tester than the control (divergent in sequence or missing or at lower copy number). Gene order reflects results of hierarchical clustering of genes performed as described in Materials and Methods. The

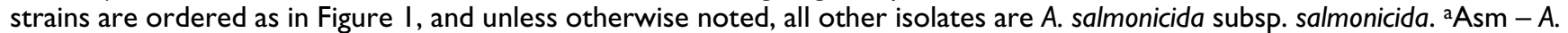
salmonicida subsp. masoucida, bAsa - A. salmonicida subsp. achromogenes, ${ }^{\mathrm{c} A s s}-\mathrm{A}$. salmonicida subsp. salmonicida. (A) All genes from the plasmid functional category. The blue bars (both light and dark) indicate genes found on plasmid 5 , and the dark blue bars correspond to predicted TTSS genes. (B) All genes from the transposon functional category. The orange bars indicate genes with strong sequence similarity to known transposases.

strains. Figure $2 \mathrm{~B}$ shows the subset of genes that are not associated with transposons or plasmids but are divergent in at least one of the fourteen A. salmonicida samples. These divergent "chromosomal" genes show some clustering of genes coding for outer membrane proteins and flagella/pili.
The number of genes divergent or absent according to the function categories assigned in Table 2 and by species/ strain is presented in Table 3. The highest degree of divergence compared to A449 can be seen for A. caviae and A. bestiarum, followed by the type strains of $A$. salmonicida subspp. masoucida and achromogenes as well as one of the 

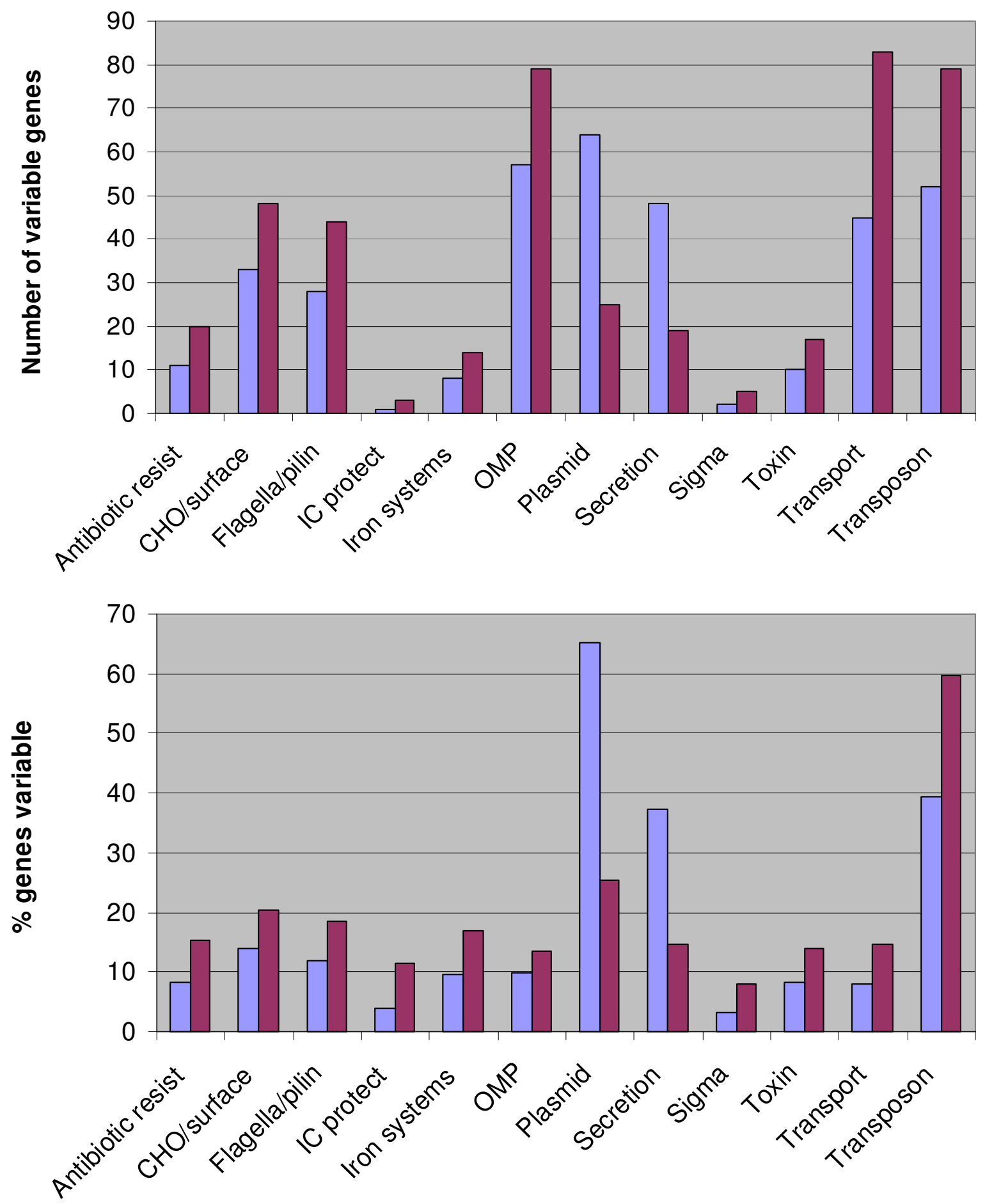

\section{Figure 4}

Variability of genes associated with different functional categories. Blue bars correspond to genes which were present at higher copy number (Log Ratio $>I$ ) in at least one of the A. salmonicida isolates that in A449. Red bars correspond to genes which were divergent or missing (Log Ratio <-I) in at least one of the A. salmonicida isolates. Upper panel: Number of variable genes assigned to each functional category. Lower panel: Percent of genes in each functional category which were variable. 
atypical samples (N2517). There was much less variation between the A. salmonicida subsp. salmonicida strains and the other A. salmonicida atypical strain (N4705). Of the A. salmonicida subsp. salmonicida strains, N2461, isolated from turbot, and SS70.1, the only isolate from a Pacific salmon species (coho salmon), showed the highest degree of variability among chromosomal genes. These data notwithstanding, there does not appear to be a strong correlation between the level of genomic variability and either host or geographical origin.

The M-CGH data for genes associated with mobile elements (plasmids and transposons) in the sixteen Aeromonas samples is shown in Figure 3. Hierarchical clustering of the plasmid-associated genes (Figure 3A) shows clustering of highly variable genes matching a known plasmid of 155 kb [plasmid 5, M. Reith - unpublished data]. A subset of genes on this plasmid matches type three secretion system (TTSS) genes found in other bacteria, which is unsurprising considering that TTSS genes can be plasmidborne in A. salmonicida subsp. salmonicida [28]. We observed genomic variability consistent with the lower intensity signal for some plasmid genes, including TTSS genes, for several strains (Figure 3A). Of these, the strain SS70.1 is an avirulent, laboratory-derived strain created by treating an A. salmonicida subsp. salmonicida strain with ethidium bromide [29,30]. This likely resulted in the loss of at least one plasmid [data not shown], which would contribute to this observation. On the other hand, many genes on plasmid 5 appear to be present in higher copy number in many of the tester strains than in A449. Figure $3 \mathrm{~B}$ shows the $\mathrm{M}$-CGH data for genes associated with transposons. Many of these genes appear to be highly divergent, present at lower copy number, or missing in various tester strains, and many of the genes match known transposases.

The number of variable genes assigned to each functional category is shown in Figure 4, as well as the percent of genes in each category that were observed to be variable. Within the function categories other than transposon or plasmid, most genes that appeared to be divergent or missing in various Aeromonas strains are associated with transport, surface carbohydrate biosynthesis, outer membrane, and flagella/pili proteins. In contrast, genes associated with secretion were most likely to be present in higher copy numbers in the tester strains compared to A449. In summary, the highest degree of variability was seen in Aeromonas genes associated with mobile elements: the plasmids or the transposons, whereas genes within the chromosome of the bacterium displayed the lowest level of variability.

\section{Discussion}

In this study, patterns of variability of the 2024 selected virulence-associated genes of A. salmonicida subsp. salmonicida strain A449 within the sixteen various test isolates of A. salmonicida and other Aeromonas species were examined. It is noteworthy that genes divergent and absent in some tester strains seem to be distributed across the entire A449 genome sequence and across all the predicted functional categories whereas genes shown to be at higher copy number than in the reference strain were clustered in selected loci associated with plasmids. The number of divergent and absent genes correlated strongly with species and subspecies boundaries. For $A$. bestiarum and $A$. caviae $\sim 16 \%$ of the genes were divergent or missing, whereas for the achromogenes and masoucida subspecies $\sim 8 \%$ of the genes were divergent or missing. The range across the various $A$. salmonicida subsp. salmonicida strains was between $0.3 \%$ and $2 \%$, again reinforcing the single clone theory for this species. Overall, for the 14 A. salmonicida isolates studied, approximately $19 \%$ of the genes were divergent in at least one sample. For comparison, our previous meta-analysis of M-CGH studies of 97 strains of C. jejuni showed $\sim 33 \%$ of the genes in the genome were divergent in at least one strain [21]. It is likely that as we examine more strains of $A$. salmonicida the number of divergent genes will increase. One interesting finding is that almost $70 \%$ of the virulence-associated genes on the DNA microarray are conserved across all the Aeromonas species. Because more than $80 \%$ of these highly conserved genes appear to be chromosomal, this suggests that the divergence of $A$. bestiarum, A. caviae, and A. salmonicida may have occurred fairly recently.

The majority of A. salmonicida subsp. salmonicida isolates studied were isolated from Atlantic salmon and gave homogenous results, i.e., there is no correlation between host or geographic origin and M-CGH patterns in subsp. salmonicida isolates. Highest variability amongst the subsp. salmonicida isolates was observed in an isolate (SS70.1) from coho salmon and in an isolate (N2461) from turbot. However, more isolates from Pacific salmon should be analyzed before drawing definite conclusions on the variation between isolates from Atlantic and Pacific salmon. The relatively low number of divergent genes in most of the A. salmonicida subsp. salmonicida strains supports the findings of Garcia et al. who identified a single clone of A. salmonicida subsp. salmonicida as responsible for most outbreaks of disease worldwide [9].

Differentiation of typical and atypical strains of A. salmonicida is important economically if it can be shown that there are significant differences in the degree of variation in the genes associated with virulence and pathogenicity, and which affect the immune response of the host. If this is the case, then accurate typing methods and differentia- 
tion between typical and atypical strains and subspecies are required for diagnostic methods and for vaccine development. Lund et al. have shown variation in the protective ability of some commercial furunculosis vaccines (whole bacterins made with typical strains) against atypical strains infecting farmed spotted wolffish [14] and halibut (cited in [14]). In this context, M-CGH provides an objective means to type clinical isolates based upon the presence, absence or divergence of a large number of genes.

Phenotypical variation amongst subsp. salmonicida isolates is rare but has been described [31]. The increased resolution of M-CGH compared to phenotypic typing can be illustrated on consideration of strain N4705 which was considered an atypical strain on phenotypical grounds. However, both M-CGH and subsequent pulsed-field gel electrophoresis [Colquhoun, unpublished results] suggest that this strain is very closely related to, and should perhaps more accurately be considered a typical strain. Similarly, atypical strain N2517, may be more accurately placed within the subspecies achromogenes based upon MCGH results.

Further comparative studies will be required to establish the level of strain resolution capable by M-CGH for aeromonads. However, in the absence of complete genome sequence data for each Aeromonas strain used, MCGH, which in this study uses over 2,000 separate genetic markers, represents a comprehensive, high- resolution methodology for comparing genome information. Recent work by our group used M-CGH to examine the quantitative relationship between the Log Ratio and probe/target identity, and these analytical processes were used in the study [27].

It is preferable that vaccine candidates be strongly conserved among strains that cause disease. The M-CGH data from these experiments will provide a list of conserved genes, sorted by function category, which can be further analyzed to generate these candidates. For example, there are bioinformatics programs available to predict sub-cellular location [32] to select candidates which may be exposed to the host immune system, or to predict adhesins [33]. These downstream analyses, in combination with M-CGH analysis will reduce the number of genes required to be cloned in order to test the immune response of their encoded proteins. These experiments are currently underway.

It must be noted that M-CGH does not reveal information about gene expression or the specific role of targeted genes in pathogenicity or host immune responses. However, it is a powerful tool in reverse vaccinology and M-CGH is a sensitive and comprehensive technique that can determine genomic variation between pathogen strains, and it also can be used as a screening tool for target identification, and/or a typing method.

\section{Conclusion}

M-CGH is a powerful first screen for vaccine target identification, and is the basis of reverse vaccinology [25], as it facilitates identification of conserved and duplicated genes associated with virulent strains. This technique may also prove useful in strain typing and epidemiological studies.

Comparative analysis of genomic data of A. salmonicida and related organisms reveals candidates common to all clinical isolates or those strains shown to be associated with virulence and disease. Our work on knock-out mutants of A449 virulence genes, combined with proteomic analysis of selected isolates confirm the results of our M-CGH analyses and will enable us to select specific antigens for vaccine development [work in progress].

The findings reported here support our initial hypotheses that variability exists between subspecies, that there is no correlation between 'typical' and 'atypical' classifications and gene variability. We also found that there is a positive correlation between the degree of variability and the functional category of the genes involved.

Future work will include the use of microarray transcript profiling experiments to further focus the choice of target genes. This will allow us to develop an ongoing, dynamic list of vaccine candidates to be used in live challenges for virulence and protection assays and then in further vaccine development.

\section{Methods \\ Bacterial strains}

Isolates of Aeromonas spp. used in this study are presented in Table 1 . The isolates were characterized as belonging to either typical or atypical groups using a limited number of biochemical tests and phenotypical characteristics. Important characteristics for differentiation were growth rates, colony size, production of brown diffusible pigment, hemolysin production, and to a lesser extent, production of acid from sucrose. The reference strain, A449 is a wild-type isolate of A. salmonicida subsp. salmonicida, kindly donated by Dr. William Kay, University of Victoria, British Columbia. All strains were grown on Tryptic Soy Agar (TSA, Difco) at $18^{\circ} \mathrm{C}$ for $24-48$ hours before genomic DNA isolation.

\section{Selection of genes for DNA microarray construction}

The draft genome sequence of A. salmonicida strain A449 [available upon request from the National Research Council of Canada, Institute for Marine Biosciences] was used as a source of the genes used in this study. ORFs were 


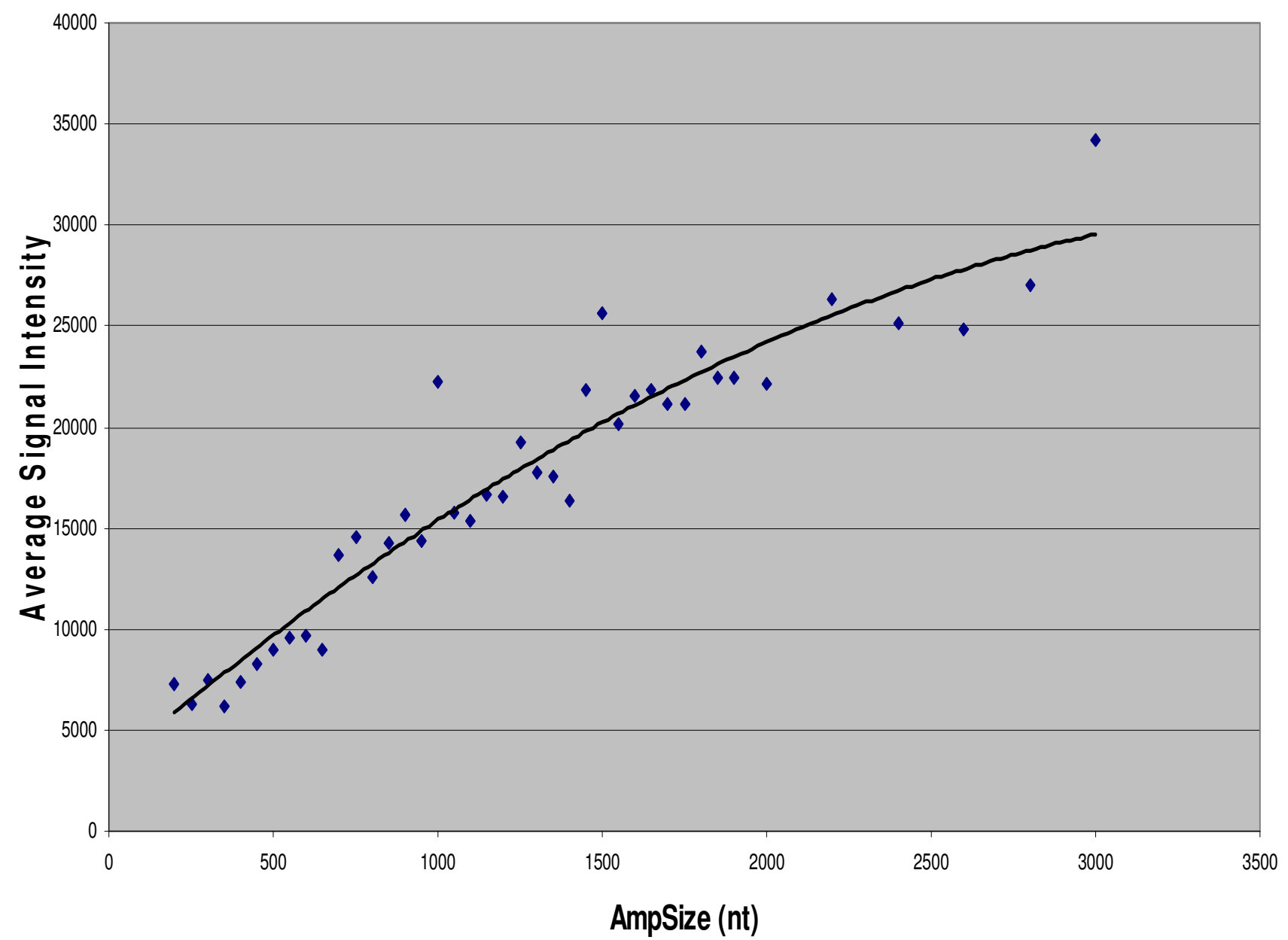

\section{Figure 5}

Variation in hybridization signal intensity with amplicon length. The average signal intensity in the control channel is plotted versus amplicon size. The amplicons were "binned" in 50 bp increments (to 1900 bp) then in 200 bp increments (from 2000 to 3000 bp). There were only 4 amplicons of size over 3000 bp.

identified using the Glimmer software package [34], and used to search for homologs among the bacterial gene subset of Genbank [35] using the BLASTP program [36]. We selected 2024 ORFs for inclusion on a DNA microarray based upon one or more of the following criteria:

i) Similarity to known virulence factors from other bacteria based on visual examination of the BLASTP analysis of the A. salmonicida genome.

ii) Presence of "virulence-associated keywords" within the gene annotations of homologs returned from BLASTP analysis. These keywords and their associated functional categories are described in Table 2. iii) Similarity to genes in the National University of Singapore Fish Pathogen Database [37].

DNA sequences corresponding to plasmids pAsa1, pAsa2 and pAsa 3 were excluded from our microarray because they only had genes for self-existence, and no virulence factors [38]. Sequences corresponding to two then-newlydiscovered plasmids (plasmids 4-5), which had not been fully characterized at the time the draft sequence was obtained, are included in the DNA microarray.

\section{Construction of an Aeromonas salmonicida A449 amplicon-based DNA microarray}

PCR primers were designed successfully for each of the 2024 ORFs described above using the Primer3 program [39] controlled by an automated script as described previ- 
ously [21]. Primer-selection parameters were standardized and included a similar predicted melting temperature (62 $\left.\pm 3^{\circ} \mathrm{C}\right)$, uniform length $(21 \mathrm{nt})$, and a minimum amplicon size of $160 \mathrm{bp}$. The average amplicon size was $890 \mathrm{bp}$ (range 164 to $4268 \mathrm{bp}$ ). Generation of PCR amplicons and fabrication of DNA microarrays were as described [21]. Details on the construction of this microarray (AsalChip1) are available [40].

\section{Genomic DNA labelling}

Genomic DNA was isolated as described [21], and fragmented by nebulization [41]. $100 \mu \mathrm{g}$ of DNA in nebulization buffer [10 mM Tris; 1 mM EDTA (pH 8.0), 35\% glycerol $(\mathrm{v} / \mathrm{v})]$ was placed in the chamber of an AeroMist Nebulizer (IPI Medical Products, Chicago, IL), and sheared by passing nitrogen gas through the chamber at 15 psi for 1 minute. The DNA was precipitated with ethanol and suspended in $100 \mu \mathrm{l}$ of $10 \mathrm{mM}$ Tris; $1 \mathrm{mM}$ EDTA ( $\mathrm{pH}$ 8.0). Typically, the DNA was fragmented to a range of 0.4 to $12 \mathrm{~kb}$ in size. $5 \mu \mathrm{g}$ of fragmented gDNA were fluorescently labelled using direct chemical coupling with the Label-IT (Mirus Corp., Madison, WI) cyanine dyes Cy3 and Cy 5 as recommended by the manufacturer. Probes were purified from unincorporated dyes by sequentially passing samples through SigmaSpin (Sigma, Oakville, ON) and Qiaquick (Qiagen, Mississauga, ON) columns. Labelled DNA sample yields and dye incorporation efficiencies were calculated using the Nanodrop ND-1000 spectrophotometer (Nanodrop, Rockland, DE).

\section{Microarray hybridizations}

The hybridization profile for each strain was obtained by co-hybridizing labelled DNA from the tester strain and from the A. salmonicida A449 (control) strain to our microarray. DNA from tester strains was labelled with Cy5 and the control strain with Cy3. Dye swaps were performed on selected strains to test for potential dye-incorporation bias. Labelled samples were normalized by selecting tester/control sample pairs with similar dye incorporation efficiencies. Equivalent amounts ( 1 to $2 \mu \mathrm{g}$ ) of labelled tester and control samples were pooled, lyophilized, and then re-suspended in $35 \mu \mathrm{l}$ of hybridization buffer [1 $\times$ DIGEasy hybridization solution (Roche, Laval, QC); $0.5 \mu \mathrm{g} / \mu \mathrm{l}$ of torulla yeast tRNA]. Probes were denatured at $65^{\circ} \mathrm{C}$ for 5 minutes and applied to the microarray. Hybridizations were performed overnight at $37^{\circ} \mathrm{C}$ under $24 \times 42$-mm glass cover slips in a highhumidity chamber. Microarrays were washed $2 \times 5$ minutes at $50^{\circ} \mathrm{C}$ in $1 \times$ SSC with $0.1 \%$ SDS, then $2 \times 5$ minutes at $50^{\circ} \mathrm{C}$ in $0.5 \times \mathrm{SSC}$, and $1 \times 5$ minutes at $50^{\circ} \mathrm{C}$ in $0.1 \times$ SSC. Slides were spun dry $(500 \times \mathrm{g}, 5$ minutes $)$ and stored in lightproof containers until scanned.

\section{Data acquisition and analysis}

Microarrays were scanned using a Chipreader laser scanner (BioRad, Mississauga, ON) according to the manufacturer's recommendations. Spot quantification, signal normalization and data visualization were performed using the program ArrayPro Analyzer (version 4.5; Media Cybernetics, Silver Spring, MD). Net signal intensities were obtained by performing local-ring background subtraction. "Tester signal" is defined as the signal intensity of the selected Aeromonas isolates labeled with appropriate fluorescent dye, while "control signal" is defined as the signal intensity of A. salmonicida strain A449 labelled with its appropriate fluorescent dye. The control signal increases with increasing amplicon size as shown in Figure 5. The ratio of tester signal to control signal for each gene was transformed to its base 2 logarithm [42], $\log _{2}$ [Tester Signal/Control Signal], referred to as "Log Ratio". Data from each channel were adjusted using cross-channel Loess normalization of the Log Ratio data and low intensity and anomalous spots were flagged and removed. Data was stored and archived using the BASE BioArray Software Environment [43].

Technical variation in our methodology was tested by selecting a subset of strains for replicate hybridizations, and treating the data from replicates separately throughout the various analyses. Consistency in the data was assessed by direct comparison of the lists of variable genes obtained from each replicate. Microarray data from sets of hybridizations were exported from BASE after removal of flagged spots, Loess normalization and averaging of data from duplicate spots. Filtering of genes based on the functional categories described in Table 2 was applied as required, and the results were analyzed using the MEV software package from TIGR [44,45]. Visualization and hierarchical clustering of microarray data, using Euclidean Distance metrics and Average Linkage Clustering, was performed in MEV using algorithms developed by Eisen et al. [46]. We generated sample trees as well as support trees based on bootstrapping genes with 1000 iterations to examine the variation of CGH profiles between the different isolates.

\section{Identification of plasmid and TTSS genes}

Chromosomal and plasmid genes present on the array had not been distinguished from each other in the original construction phase. When the sequences of plasmids 4-5 became available, i.e. were separated from the chromosomal genome assembly as it progressed, the BLAST software package [47] was used to compare the nucleotide sequences of all ORFs on the A. salmonicida microarray chip to the sequences of plasmids $4-5$, and thus identify them. We also created a database of all known bacterial TTSS genes and used BLAST to identify ORFs within the A. salmonicida genome sequence with high similarity to these 
genes. These results were used to generate gene lists for uploading into MEV to characterize observed gene clusters.

\section{List of abbreviations}

M-CGH: microarray-based comparative genomic hybridization; gDNA: genomic DNA; ORF: open reading frame; nt: nucleotides; psi: pounds per square inch

\section{Authors' contributions}

JHEN co-led the conception and design of the study, contributed to the design of the microarray, participated in the interpretation of data, drafted and co-wrote the manuscript. WAF carried out analysis and interpretation of microarray data, produced the figures, assisted in production of the microarray, and contributed to writing the manuscript. CCL and OLM performed microarray hybridizations, generated microarray data, and assisted in production of the microarray. SJF identified the genes and performed the annotation of the draft version of genome. ENT participated in the design of the study and interpretation of data. CDC participated in the design of the study and performed microarray hybridizations. JMB participated in the selection of virulence targets for the array, and contributed to writing the manuscript. DJC provided several strains, participated in the interpretation of data, and in the writing of the manuscript. MER provided the draft sequence of the genome, and contributed to writing the manuscript. LLB co-led the conception and design of study, designed and built the DNA microarray, participated in the interpretation of data, drafted and co-wrote the manuscript. All authors submitted comments on drafts, and read and approved the final manuscript.

\section{Acknowledgements}

Funding for this work has been provided to LLB, JMB, WAF, OLM, JHEN, MER, and ENT through the National Research Council Genomics and Health Initiative. The expert technical assistance of Sandra Sperker, Darren Sarty and Brian Agnew is appreciated. We are grateful to Dr. William Kay (University of Victoria, Victoria, BC) for his kind donation of the A449 strain and to Dr. Gilles Olivier (Fisheries and Oceans Canada, Moncton, NB) and Dr. Joanne Constantine (BC Ministry of Agriculture, Food, and Fisheries, Victoria, BC), for their kind donations of $A$. salmonicida clinical isolates. We thank Dr. Kyoung Park for critically reviewing the manuscript. This is NRC Publication \# 2005-42556.

\section{References}

I. Canadian Aquaculture Industry Alliance 2006 [http:// www.aquaculture.ca/EnglishWeb.html].

2. E-M B: Furunculosis: the history of the diseases and of disease research. In Furunculosis - Multidisciplinary Fish Disease Research Edited by: Bernoth EM, A.E. E, P.J M, G. O and P. S. London, Academic Press; 1997:I-20.

3. Hiney M, Olivier G: Furunculosis (Aeromonas salmonicida). In Fish Diseases and Disorders III: Viral, Bacterial and Fungal Infections Edited by: Woo PTK and Bruno DW. Oxford, CAB Publishing; 1999:34I-425.

4. Wiklund T, Dalsgaard I: Occurrence and significance of atypical Aeromonas salmonicida in non-salmonid and salmonid fish species: a review. Dis Aquat Organ 1998, 32:49-69.
5. Garrity GM, Winters M, Searles DB: Taxonomic outline of the procaryotic genera. In Bergey's Manual of Systematic Bacteriology New York, Sprimger Verlag; 200I: I-39.

6. K.H. B, H. F, H-J. S, W K: Aeromonas salmonicida from salmonids and cyprinids - serological and cultural identification. J Vet Med 1986, B33:777-783.

7. McCarthy DH, Roberts RJ: Furunculosis in fish - the present stage of our knowledge. In Advances in Aquatic Microbiology Edited by: Droop MR and Jannasch HW. London, Academic Press; 1980:293-341.

8. Austin B, Austin DA, Dalsgaard I, Gudmundsdottir BK, Hoie S, Thornton JM, Larsen JL, O'Hici B, Powell R: Characterization of atypical Aeromonas salmonicida by different methods. Syst Appl Microbiol 1998, 21:50-64.

9. Garcia JA, Larsen JL, Dalsgaard I, Pedersen K: Pulsed-field gel electrophoriesis analyis of Aeromonas salmonicida ssp. salmonicida. FEMS Microbiol Lett 2000, 190:163-166.

10. Dalsgaard I, Nielsen B, Larsen JL: Characterization of Aeromonas salmonicida subsp. salmonicida: a comparative study of strains of different geographic origin. J Appl Bacteriol 1994, 77:21-30.

II. Dalsgaard I, Gudmundsdottir BK, Helgason S, Hoie S, Thoresen OF, Wichardt UP, Wiklund T: Identification of atypical Aeromonas salmonicida: inter-laboratory evaluation and harmonization of methods. J Appl Microbiol 1998, 84:999-1006.

12. Miyata M, Aoki T, Inglis V, Yoshida T, Endo M: RAPD analysis of Aeromonas salmonicida and Aeromonas hydrophila. J Appl Bacteriol 1995, 79:181-185.

13. Inglis V, Colquhoun D, Pearson MD, Miyata M, Aoki T: Analysis of DNA relationships among Aeromonas species by RAPD (randomly amplified polymorphic DNA) typing. Aquaculture International 1996, 4:43-53.

14. Lund V, Espelid S, Mikkelsen H: Vaccine efficacy in spotted wolffish Anarhichas minor: relationship to molecular variation in A-layer protein of atypical Aeromonas salmonicida. Dis Aquat Organ 2003, 56:3I-42.

15. O'Hici B, Olivier G, Powell R: Genetic diversity of the fish pathogen Aeromonas salmonicida demonstrated by random amplified polymorphic DNA and pulsed-field gel electrophoresis analyses. Dis Aquat Organ 2000, 39:109-119.

16. Whittington RJ, Djordjevic SP, Carson J, RB C: Restriction endonuclease analysis of atypical Aeromonas salmonicida isolates from goldfish Carassius auratus, silver perch Bidyanus bidyanus, and greenback flounder Rhombosolea tapirina in Australia. Dis Aquat Org 1995, 22:185-191.

17. Sørum H, Kvello JH, Hastein T: Occurrence and stability of plasmids in Aeromonas salmonicida subsp. salmonicida isolated fom salmonids with furunculosis. Dis Aquat Org 1993, 16:199-206.

18. Sørum H, Holstad G, Lunder T, Hastein T: Grouping by plasmid profiles of atypical Aeromonas salmonicida isolated from fish, with special reference to salmonid fish. Dis Aquat Organ 2000, 4I: I59-I7I.

19. Hanninen ML, Hirvela-Koski V: Molecular and phenotypic methods for the characterization of atypical Aeromonas salmonicida. Vet Microbiol 1997, 56:147-158.

20. Nielsen B, Olsen JE, Larsen JL: Ribotyping of Aeromonas salmonicida subsp. salmonicida. Dis Aquat Org 1994, I 8: I 55- I58.

21. Taboada EN, Acedillo RR, Carrillo CD, Findlay WA, Medeiros DT, Mykytczuk OL, Roberts MJ, Valencia CA, Farber JM, Nash JH: Largescale comparative genomics meta-analysis of Campylobacter jejuni isolates reveals low level of genome plasticity. J Clin Microbiol 2004, 42:4566-4576.

22. Soule M, Cain K, LaFrentz S, Call DR: Combining suppression subtractive hybridization and microarrays to map the intraspecies phylogeny of Flavobacterium psychrophilum. Infect Immun 2005, 73:3799-3802.

23. Borucki MK, Kim SH, Call DR, Smole SC, Pagotto F: Selective discrimination of Listeria monocytogenes epidemic strains by a mixed-genome DNA microarray compared to discrimination by pulsed-field gel electrophoresis, ribotyping, and multilocus sequence typing. J Clin Microbiol 2004, 42:5270-6.

24. Ong C, Ooi CH, Wang D, Chong H, Ng KC, Rodrigues F, Lee MA, Tan P: Patterns of large-scale genomic variation in virulent and avirulent Burkholderia species. Genome Res 2004, 14:2295-2307. 
25. Rappuoli R: Reverse vaccinology, a genome-based approach to vaccine development. Vaccine 200I, 19:2688-269I.

26. Bricknell IR, Bowden TJ, Verner-Jeffreys DW, Bruno DW, Shields RJ, Ellis AE: Susceptibility of juvenile and sub-adult Atlantic halibut (Hippoglossus hippoglossus L.) to infection by Vibrio anguillarum and efficacy of protection induced by vaccination. Fish Shellfish Immunol 2000, I 0:319-327.

27. Taboada EN, Acedillo RR, Luebbert CC, Findlay WA, Nash JH: A new approach for the analysis of bacterial microarray-based Comparative Genomic Hybridization: insights from an empirical study. BMC Genomics 2005, 6:78.

28. Stuber K, Burr SE, Braun M, Wahli T, Frey J: Type III secretion genes in Aeromonas salmonicida subsp salmonicida are located on a large thermolabile virulence plasmid. J Clin Microbiol 2003, 4l:3854-3856.

29. Burr SE, Wahli T, Segner H, Pugovkin D, Frey J: Association of Type III secretion genes with virulence of Aeromonas salmonicida subsp. salmonicida. Dis Aquat Org 2003, 57:|67-I7|

30. Hackett JL, Lynch WH, Paterson WD, Coombs DH: Extracellular Protease, Extracellular Haemolysin, and Virulence in Aeromonas salmonicida. Can J Fish Aquat Sci I 984, 4 I : I 354- I 360.

31. Koppang EO, Fjølstad M, Melgård B, Vigerust M, Sørum H: Non-pigment-producing isolates of Aeromonas salmonicida subspecies salmonicida: isolation, identification, transmission and pathogenicity in Atlantic salmon, Salmo salar L. Journal of Fish Diseases 2000, 23:39-48.

32. Gardy JL, Laird MR, Chen F, Rey S, Walsh CJ, Ester M, Brinkman FS: PSORTb v.2.0: expanded prediction of bacterial protein subcellular localization and insights gained from comparative proteome analysis. Bioinformatics 2005, 21 :617-623.

33. Sachdeva G, Kumar K, Jain P, Ramachandran S: SPAAN: a software program for prediction of adhesins and adhesin-like proteins using neural networks. Bioinformatics 2005, 21:483-491.

34. Delcher AL, Harmon D, Kasif S, White O, Salzberg SL: Improved microbial gene identification with GLIMMER. Nucleic Acids Res 1999, 27:4636-4641.

35. National Center For Biotechnology Information's Prokaryotic Genomes Database [http://www.ncbi.nlm.nih.gov/genomes/ Iproks.cgi]

36. Altschul SF, Madden TL, Schaffer AA, Zhang J, Zhang Z, Miller W, Lipman DJ: Gapped BLAST and PSI-BLAST: a new generation of protein database search programs. Nucleic Acids Res 1997, 25:3389-3402.

37. Fish Pathogen Database 2006 [http://dbsdb.nus.edu.sg/fpdb/ index.html].

38. Boyd J, Williams J, Curtis B, Kozera C, Singh R, Reith M: Three small, cryptic plasmids from Aeromonas salmonicida subsp. salmonicida A449. Plasmid 2003, 50:131-144.

39. Rozen S, Skaletsky H: Primer3 on the WWW for general users and for biologist programmers. Methods Mol Biol 2000, 132:365-86.

40. AsalChip Description 2006 [http://www.ibs-isb.nrc-cnrc.gc.ca/gly cobiology/asalchips e.html].

4I. Bodenteich AS, Chissoe Y, Wang F, Roe BA: Shotgun cloning as the strategy of choice to generate templates for high throughput dideoxynucleotide sequencing. In Automated DNA sequencing and analysis techniques Edited by: Adams MD, Fields $C$ and Venter C. London, UK: Academic Press; 1994:42-50.

42. Smyth GK, Yang YH, Speed T: Statistical issues in cDNA microarray data analysis. Methods Mol Biol 2003, 224: I I I-I36.

43. Saal LH, Troein C, Vallon-Christersson J, Gruvberger S, Borg A Peterson C: BioArray Software Environment (BASE): a platform for comprehensive management and analysis of microarray data. Genome Biol 2002, 3:SOFTWARE0003.

44. Saeed Al, Sharov V, White J, Li J, Liang W, Bhagabati N, Braisted J, Klapa M, Currier T, Thiagarajan M, Sturn A, Snuffin M, Rezantsev A, Popov D, Ryltsov A, Kostukovich E, Borisovsky I, Liu Z, Vinsavich A, Trush V, Quackenbush J: TM4: a free, open-source system for microarray data management and analysis. Biotechniques 2003, 34:374-8.

45. TM4 Microarray Software Suite 2006 [http://www.tm4.org/ mev.html].

46. Eisen MB, Spellman PT, Brown PO, Botstein D: Cluster analysis and display of genome-wide expression patterns. Proc Natl Acad Sci U S A 1998, 95:|4863-|4868.
47. Altschul SF, Gish W, Miller W, Myers EW, Lipman DJ: Basic local alignment search tool. J Mol Biol 1990, 2 I 5:403-4I0.
Publish with Biomed Central and every scientist can read your work free of charge

"BioMed Central will be the most significant development for disseminating the results of biomedical research in our lifetime. "

Sir Paul Nurse, Cancer Research UK

Your research papers will be:

- available free of charge to the entire biomedical community

- peer reviewed and published immediately upon acceptance

- cited in PubMed and archived on PubMed Central

- yours - you keep the copyright 